\title{
A rare case of bilateral nasolabial cysts
}

\author{
Priya Sethukumar, Ali Taghi, Romana Kuchai
}

Department of Otolaryngology, Imperial College Healthcare NHS Trust, London, UK

\section{Correspondence to} Priya Sethukumar, priya00sk@gmail.com

Accepted 22 February 2015

\section{SUMMARY}

Nasolabial cysts are rare non-odontogenic cystic lesions representing around $0.7 \%$ of all maxillofacial cysts. They usually present as unilateral painless swellings, sometimes with epiphora and dacryocystitis as well as pain in cases of rapid growth or infection. We have reviewed the literature and present an extremely rare case of bilateral nasolabial cysts in a young Afro-Caribbean man presenting with chronic nasal blockage, epiphora and rhinorrhoea. We describe our successful surgical management using a sublabial approach for complete excision, leading to a disease-free outcome at 6 months follow-up. Other modalities have been described, from endoscopic marsupialisation to simple aspiration. However, with the exception of complete surgical excision, all other surgical techniques are associated with a high recurrence rate. We therefore advocate complete surgical excision as described below for optimal results.

\section{BACKGROUND}

Nasolabial cysts are very rare non-odontogenic cystic lesions, usually presenting with a painless swelling of the nasolabial region. Historically, the Austro-Hungarian anatomist Zuckerkandl first described them in 1882 .

The pathogenesis remains controversial but nasolabial cysts are considered to be a type of retention cyst. Subsequently, embryological theories have also been put forward. ${ }^{1}$ Currently, opinion broadly divides into two aetiological distinctions. The first is that of a 'fissural cyst' being created due to entrapment of epithelial cells in mesenchyme following fusion of medial and lateral nasal processes and maxillary prominence. ${ }^{2}{ }^{3}$ The second theory suggests a persistence of remnant epithelium entrapped during embryogenesis, arising from the lower part of the nasolacrimal duct. ${ }^{4}$

Most patients present with a swelling in the upper lip, nasal ala or as a fullness in the canine fossa, which can become painful if the cyst is infected. Patients are often in their fourth or fifth decade and commonly female. ${ }^{5}$

We present an extremely rare description of bilateral nasolabial cysts in a young Afro-Caribbean man with recommendations for surgical management.

\section{CASE PRESENTATION}

A 36-year-old Afro-Caribbean man with no significant medical history presented with chronic painless swelling in the right nasal alar region, becoming increasingly worse over the past 6 weeks. He also described intermittent anosmia, rhinorrhoea and ation, there was a soft, non-tender, fluctuant mass noted in the right nasal sill/alar region. epiphora for the same duration of time. On examin-

\section{INVESTIGATIONS}

The patient subsequently underwent CT and MRI of his sinuses, which showed evidence of bilateral nasolabial cysts, $25 \mathrm{~mm}$ in the floor of the right nasal cavity and a similar mass in the left of $23 \mathrm{~mm}$, causing pressure erosion of the anterior maxilla. Both masses were fairly well defined with intermediate to low density but not clearly exhibiting cystic characteristics. Both contacted the columella. The appearances were unusual and prompted a differential diagnosis including malignancy as well as inflammatory masses such as bilateral infected nasolabial cysts.

An MRI with gadolinium was urgently arranged, which confirmed the two lesions to be entirely cystic with only thin peripheral enhancement.

\section{DIFFERENTIAL DIAGNOSIS}

- Infection: including dental abscess of canine space.

- Inflammation: post-trauma.

- Dermoid and epidermoid cysts (These are associated with yellow discolouration of the overlying mucosa. With nasolabial cysts, the mucosa conserves its pink hue or appears blue-tinged. Furthermore, these are more commonly diagnosed in childhood, in contrast to nasolabial cysts being more common in adults). ${ }^{6}$

- Odontogenic cysts.

- Neoplasia: including minor salivary gland tumours and schwannoma (both of which are extremely rare).

- Other: lip swelling and granulomatous cheilitis as a manifestation of Melkersson-Rosenthal syndrome (comprising facial nerve palsy, furrowed/ plicated tongue and granulomatous cheilitis).

\section{TREATMENT}

The patient successfully underwent surgical excision under general anaesthesia using a sublabial approach. Several surgical techniques have been described, including: complete surgical excision, endoscopic marsupialisation, simple aspiration, incision and drainage, injection of sclerotic agents, marsupialisation and endoscopic intranasal microdebridement. However, with exception of complete surgical excision, all other surgical techniques are associated with a high recurrence rate. ${ }^{7}$

We advocated complete surgical excision under general anaesthesia using a bilateral sublabial incision, after infiltrating the incision site with local anaesthetic to decrease intraoperative bleeding. Intraoperatively, tissue was dissected until the smooth, well circumscribed cystic lesions were exposed. Consistent with the preoperative imaging 


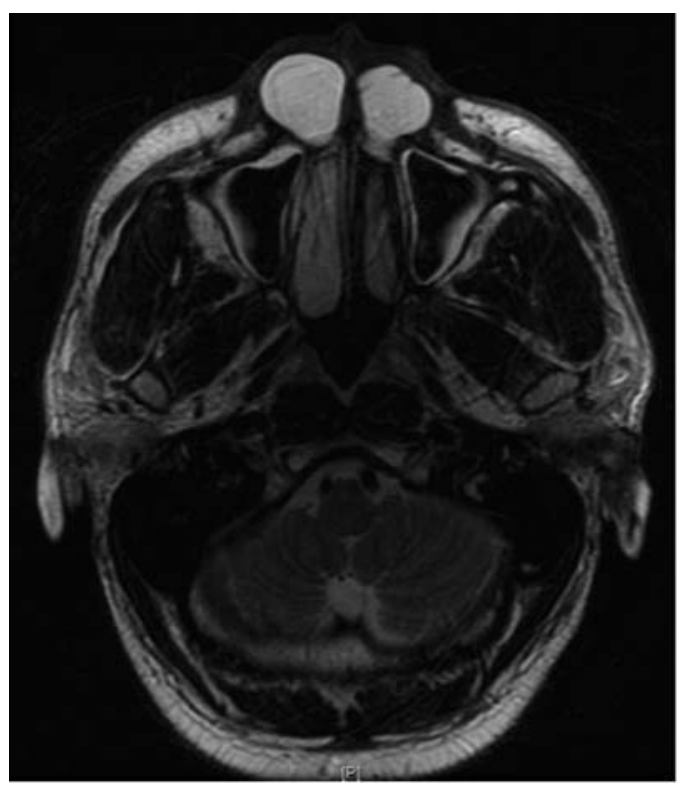

Figure 1 MRI with contrast demonstrating bilateral nasolabial cysts.

(figure 1), we noted the lesions to be completely extraosseous with no adhesion to the underlying bone (figure 2). Although these cysts were relatively easy to remove from the surrounding soft tissues, there is always the risk of tearing or rupture. In our case, part of the nasal floor mucosa was removed with the cyst due to a very difficult dissection. Nevertheless, the cyst can be easily and completely removed without remnant of the cystic wall (figure 3). A defect of the nasal floor mucosa is not a serious problem and the area usually heals well. The resultant defect will decrease in size with time and convert into an air containing sinus.

\section{OUTCOME AND FOLLOW-UP}

No subsequent dressing or packing was required and the patient was discharged on the same day. Six months postoperatively, the patient is making an uneventful recovery with no signs of recurrence.

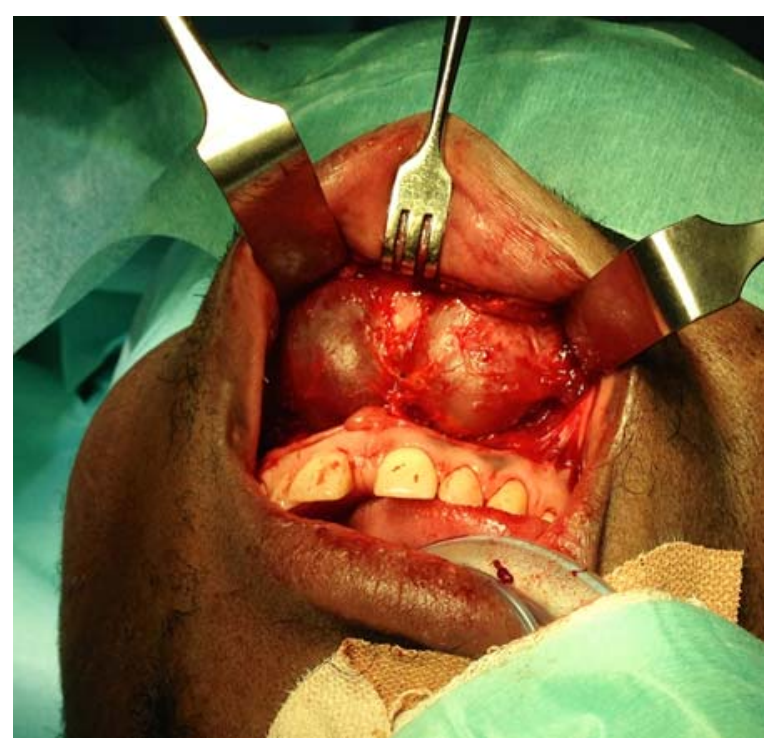

Figure 2 Well defined bilateral nasolabial cysts.

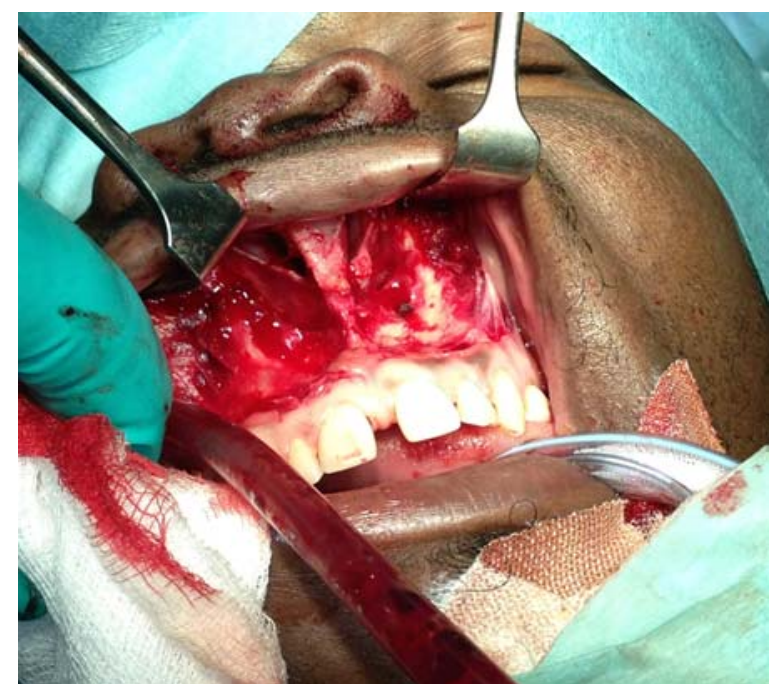

Figure 3 Postexcision.

Postoperative histological tissue analysis revealed evidence of fibrovascular stroma in keeping with nasolabial cysts, containing convoluted cystic spaces lined by respiratory type epithelium with squamous metaplasia (figures 4 and 5).

The figures above depict a cyst with fibrovascular wall lined partly by respiratory type epithelium and partly by nonkeratinising squamous epithelium consistent with nasolabial cyst. There are no features of atypia or malignancy.

\section{DISCUSSION}

Nasolabial cysts are a rare entity and represent around $0.7 \%$ of all maxillofacial cysts. ${ }^{5}$ The majority are unilateral with a leftsided preponderance, ${ }^{3}$ and women aged 40 years seem to be more frequently affected. ${ }^{2} 8$ Our case of bilateral cysts in a young man is therefore even rarer. However, the clinical features are characteristic, including the longstanding duration of symptoms and location (submucous and at the ala of the nose). The variation in size in the literature has been attributed to the fact that, especially when infected, around $50 \%$ of these cysts can spontaneously drain into the mouth or nose. ${ }^{3} 79$ This could also explain the rhinorrhoea experienced by our patient.

Most patients present pain free with problems of nasal obstruction and deformity. Others can present with pain, especially in cases of infection. Epiphora and dacryocystitis are not

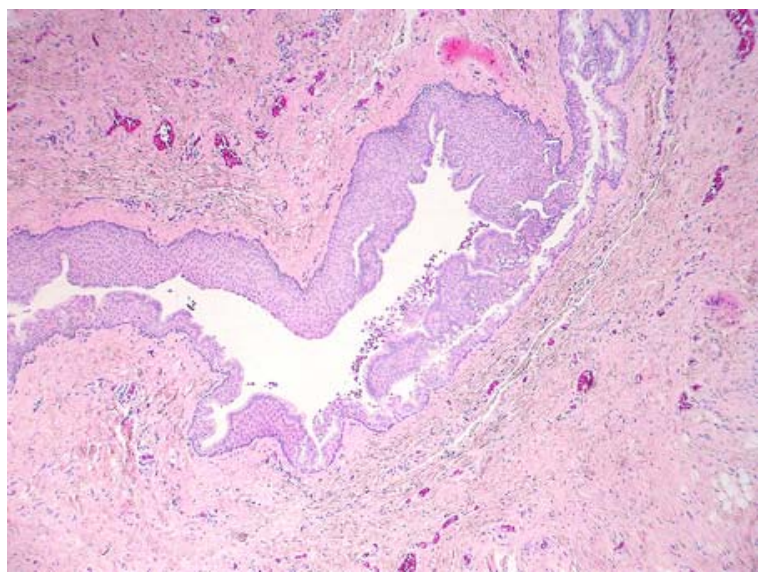

Figure 4 Nasolabial cyst (H\&E stain, $\times 50$ magnification). 


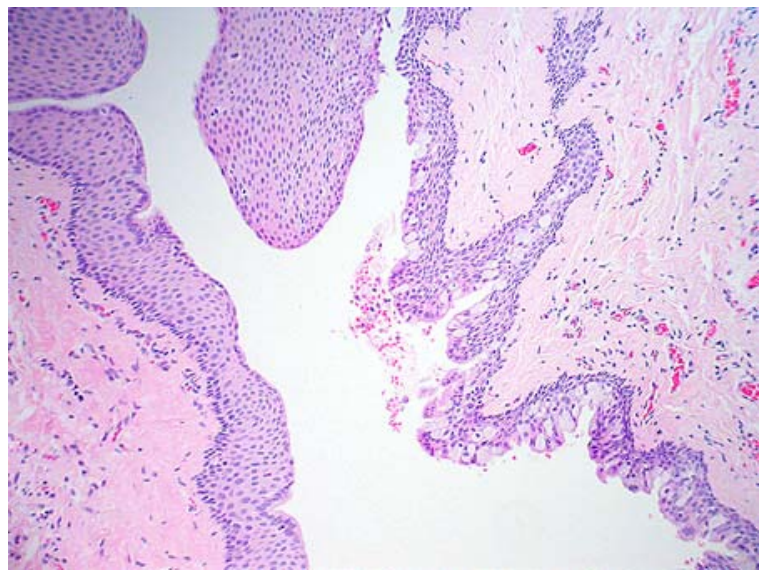

Figure 5 Nasolabial cyst (H\&E stain, $\times 100$ magnification).

uncommon symptoms, in keeping with the fact that lacrimal fluid drains medially from the corneal surface into the lacrimal sac, then into the nasolacrimal duct, which opens into the inferior nasal meatus. Nasolabial cysts are usually located in close proximity to the nasolabial duct and its opening into the inferior nasal meatus, and can easily compromise lacrimal drainage, especially in bilateral cases, as experienced by our patient. With this anatomical proximity in mind, the possibility of an association between nasolabial cysts and the presence of dacryocystitis would therefore be unsurprising. It may well be that our patient, presenting with rhinorrhoea and epiphora, was developing features of dacryocystitis. Indeed, cases in the literature have been reported which corroborate this link: Kyrmizakis et al ${ }^{10}$ reported a case of a 48 -year-old woman presenting with bilateral chronic dacryocystitis attending for dacryocystorhinostomy who was subsequently found to have bilateral nasolabial cysts on CT. Their excision together with unilateral dacryocystorhinostomy completely relieved her symptoms. Lee and Christmas also describe a case of bilateral nasolabial cysts presenting in a patient with chronic epiphora. ${ }^{11}$ Therefore it would seem that epiphora together with rhinorrhoea are important presenting features in our patient and, as discussed above, could reflect an anatomical-embryological association between dacryocystitis and the presence of bilateral nasolabial cysts.

With regard to aetiology, two main theories exist: that of embryonic nasal respiratory epithelium forming fissural cysts when entrapped in a facial cleft after fusion of medial and lateral nasal processes. ${ }^{12}$ The second theory, now being more widely supported, suggests misplaced remnants from the nasolacrimal duct persisting, ${ }^{1} 13$ corroborated by similarities in histology. These cysts are often lined by pseudostratified/stratified ciliated columnar epithelium with frequent goblet cells, thus favouring a nasolacrimal origin. The observed stratified squamous epithelialisation could be metaplastic change secondary to pressure effects. Indeed, in a scanning electron microscopic examination conducted by $\mathrm{Su}$ et al, ${ }^{14}$ the cilia that had been noted on light microscopy were found to be short globular microvilli most likely adapting to an absence of stimulation from air.

An array of differential diagnoses exist, including dental abscess, sebaceous cysts or implanted epidermal inclusion cysts and salivary gland neoplasia, to name but a few. ${ }^{3}$ Diagnosis is initially made clinically, however, CT and MRI imaging is undoubtedly useful to determine the extent and boundaries of the lesion, as well as helpful in planning operative intervention to obtain conclusive histological diagnosis.

In terms of operative intervention, the treatment of choice is complete surgical excision, which we have described using a sublabial approach. ${ }^{1}{ }^{3}{ }^{8}$ Recently, some success has been reported in transnasal endoscopic marsupialisation which, apart from offering the benefits of minimally invasive surgery, has reportedly been undertaken under local anaesthetic ${ }^{15}$ in outpatient settings. ${ }^{9}$ It could be argued that there is a role for this surgery in those patients with multiple comorbidities in whom a general anaesthetic would be unsuitable.

\section{Learning points}

- Nasolabial cysts are a rare entity and represent around $0.7 \%$ of all maxillofacial cysts. ${ }^{5}$

- The need for surgical excision is threefold: to optimise function, to correct deformity and in order to obtain formal histological diagnosis, given the wide differential.

- With the exception of complete surgical excision, all other techniques are associated with a high recurrence rate.

- Regardless of surgical approach, it is vital that cysts are removed intact to prevent recurrence.

Acknowledgements The authors would like to acknowledge and thank Dr Ann Sandison, Consultant Histopathologist, Imperial College Healthcare NHS Trust.

Competing interests None.

Patient consent Obtained.

Provenance and peer review Not commissioned; externally peer reviewed.

\section{REFERENCES}

1 Klestadt WD. Nasal cysts and the facial cleft cyst theory. Ann Otol Rhinol Laryngol 1953;62:84.

2 el-Din K, el-Hamd AA. Nasolabial cysts: a report of eight cases and a review of the literature. J Laryngol Otol 1999;113:747-9.

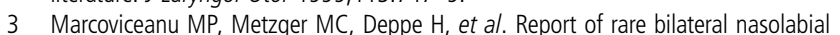
cysts. J Craniomaxillofac Surg 2009;37:83-6.

4 Karmody CS, Gallagher JC. Nasoalveolar cyst. Ann Otol Rhinol Laryngol 1972:81:278-83.

5 Choi JH, Cho JH, Kang HJ. Nasolabial cyst: a retrospective analysis of 18 cases. Ear Nose Throat J 2002;81:94-6.

6 Nixdorf DR, Peters E, Lung KE, et al. Clinical presentation and differential diagnosis of nasolabial cyst. J Can Dent Assoc 2003;69:146-9.

7 Kuriloff DB. The nasolabial cyst-nasal hamartoma. Otolaryngol Head Neck Surg 1987;96:268-72.

8 Perez AJ, Castle JT. Nasolabial cyst. Head Neck Pathol 2013;7:155-8.

9 Mutaz B, Pinar E, Calli C, et al. Endonasal endoscopic approach for recurrent nasolabial cyst. J Craniofac Surg 2012:23:e438-40.

10 Kyrmizakis DE, Lachanas VA, Benakis AA, et al. Bilateral nasolabial cysts associated with recurrent dacryocystitis. J Laryngol Otol 2005;119:412-14.

11 Lee J, Christmas PI. Bilateral nasolabial cysts: a case report. $N$ Z Dent J 2009;105:43-6.

12 Yuen HW, Julian CY, Samuel CL. Nasolabial cysts: clinical features, diagnosis, and treatment. Br J Oral Maxillofac Surg 2007:45:293-7.

13 Parwani R, Parwani S, Wanjari S. Diagnosis and management of bilateral nasolabial cysts. J Oral Maxillofac Pathol 2013;17:443-6.

14 Su CY, Huang HT, Liu HY, et al. Scanning electron microscopic study of the nasolabial cyst: its clinical and embryologic implications. Laryngoscope 2006;116:307-11.

15 Kajla P, Lata J, Agrawal R. Nasolabial cyst: review of literature and case report. J Maxillofac Oral Surg 2014;13:227-30. 


\section{Rare disease}

Copyright 2015 BMJ Publishing Group. All rights reserved. For permission to reuse any of this content visit http://group.bmj.com/group/rights-licensing/permissions.

BMJ Case Report Fellows may re-use this article for personal use and teaching without any further permission.

Become a Fellow of BMJ Case Reports today and you can:

- Submit as many cases as you like

- Enjoy fast sympathetic peer review and rapid publication of accepted articles

- Access all the published articles

- Re-use any of the published material for personal use and teaching without further permission

For information on Institutional Fellowships contact consortiasales@bmjgroup.com

Visit casereports.bmj.com for more articles like this and to become a Fellow 